\title{
EXPERIENCE IN THE OPERATION OF THE INTERNATIONAL FUSION SUPERCONDUCTING MAGNET TEST FACILITY*
}

\author{
William A. Fietz \\ U.S. Department of Energy, ${ }^{\dagger}$ ER-90 GTN, \\ Washington, D.C.
}

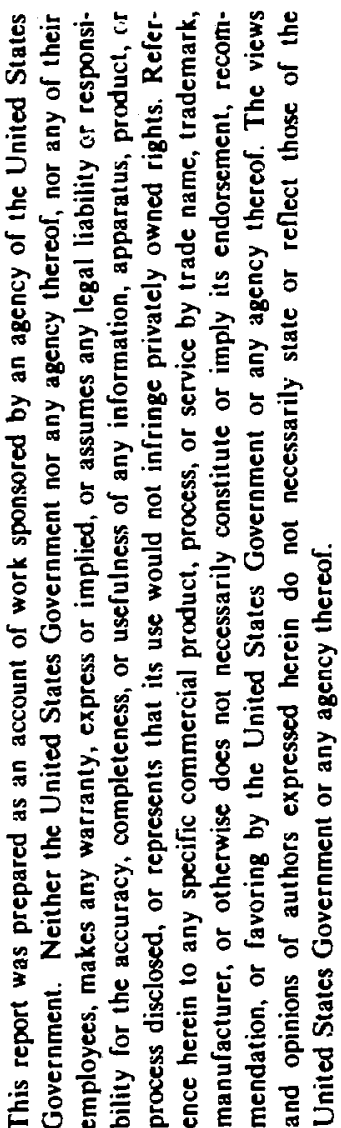

\section{ABSTRACT}

The International Fusion Superconducting Magnet Test Facility (IFSMTF) was placed under vacuum in October 1985 and cooled in Jenuary 1986. It remained at cryogenic temperatures until September 1987, when testing was completed. This paper is an account of the activities of cooling, testing, and maintaining the system during this period. The facility contained six superconducting magnets, arranged in a toroidal array. Each of these D-shaped magnets weighed 40-50 tonnes and was about $5 \mathrm{~m}$ by $10 \mathrm{~m}$. The refrigerator system provided atmospheric liquid helium ( $\mathrm{LHe}$ ), about $5000 \mathrm{~L}$ in the three pool-boiling coils and the leads, plus a storage capacity of $21,000 \mathrm{~L}$. In addition, the three forced-flow coils were supplied with up to $300 \mathrm{~g} / \mathrm{s}$ of single-phase heljum at $3.8 \mathrm{~K}$ and $15 \mathrm{~atm}$. A crew of three or four trained, certified operators handled the cryogenic facility on a 24-h basis for most of the daily activities. Detailed records were maintained, reports of unusual events were prepared, and a continuous record of availability was accumulated. At the end of the 22-month perind of operation, the cumulative availability was $57 \%$.

\section{INTRODUCTION}

A multinational program of cooperative research, development, demonstrations, and exchanges of information on superconducting magnets for fusion was initiated in 1977 under an International Energy Agency (IEA) agreement. The first major step in the development of toroidal field (TF) magnets was called the Large Coil Task (LCT). Participants in LCT were the U.S. Department of Energy (DOE), the European Atomic Energy Community (EURATOM), the Japan Atomic Energy Research Institute (JAERI), and the Département Féderal de l'Interieur of Switzeriand.

The goals of LCT were to obtain experimental data, to demonstrate reliable operation of large superconducting coils, and to prove design principles and fabrication techniques being considered for the toroidal magnets of thermonuclear reactors. These goals were to be accomplished through coordinated but largely independent design, development, and construction of six test coils, followed by collaborative testing in a compact toroidal test array at magnetic fields of $8 \mathrm{~T}$ and higher.

'Research sponsored by the Office of Fusion Energy, U.S. Department of Energy, under cuntract DE-AC05-84OR21400 with Martin Marietta Energy Systems, Inc.

${ }^{\dagger}$ On axignment from Oak Ridge National Laboratory.

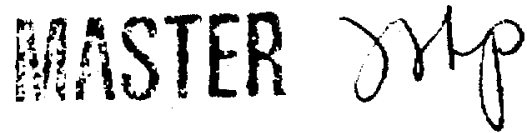




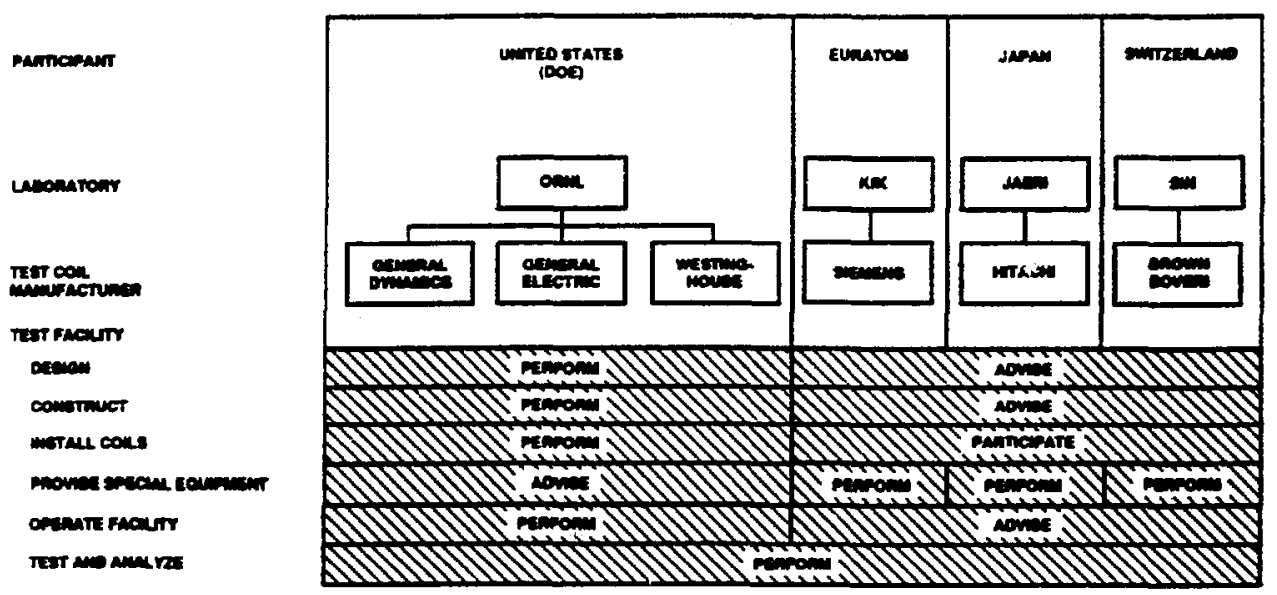

Fig. 1. Responsibilities in the IEA Large Coil Task.

The United States built and operated the test facility at Oak Ridge and provided three test coils. The other participants provided one coil each. Information on design and manufacturing and all test data were shared by all the participants. Each LCT team included a government laboratory and an industrial partner. The team arrangements and the division of responsibilities are shown in Fig. 1.

The last coil was completed in 1985, and the test assembly was ready in Ortober of that year. Just before the facility was closed in preparation for testing, it appeared as shown in Fig. 2.

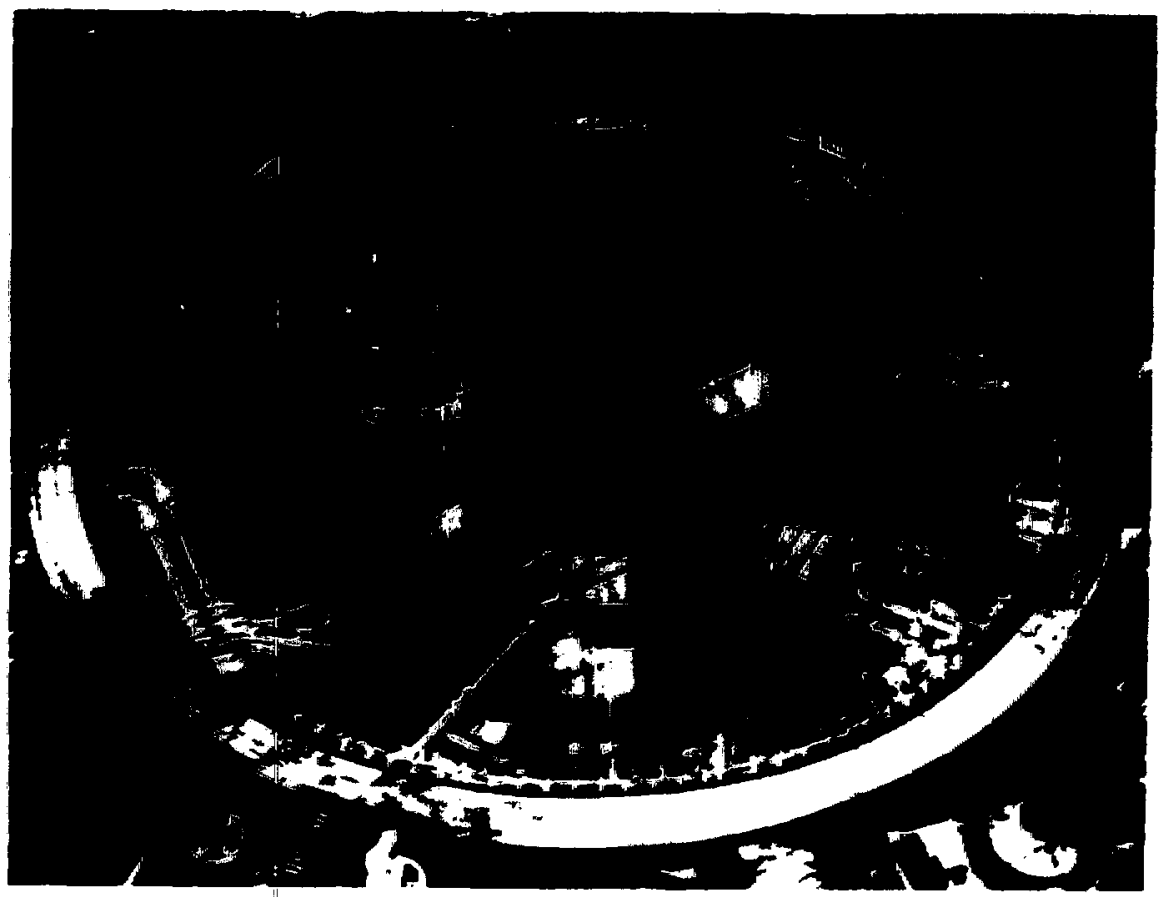

Fig. 2. Test stand with six LCT coils-October 1985. 
Over the next 22 months, extensive testing was performed. This paper summarizes the operations during the testing period, including cooldown, testing, operations, repairs, and maintenance. The overall performance $\mathrm{c}$ in be described as very good, both in the coil performance [1] and in the availabilit! of the system.

\section{SYSTEM DESCRIPTION}

The facility consisted of seven subsystems: the vacuum system, the test stand structure, the pulsed field assembly, the helium system, the liquid nitrogen (LN) system, the electric power system, and the instrumentation and control system. These are briefly described below. More detail is available in the final report [1].

The vacuum system. Tank vacuum was maintained by a $1-m$ oil diffusion pump (with a pumping speed $v=55,000 \mathrm{~L} / \mathrm{s})$, two turbomolecular pumps $(v=3450 \mathrm{~L} / \mathrm{s})$, and four mechanical roughing pumps $(v=2000 \mathrm{~L} / \mathrm{s})$.

The cylindrical, 10.7-m-ID tank had a flat bottom and a dished head, as shown in Fig. 3. Its enclosed volume was $960 \mathrm{~m}^{3}$, of which $80 \mathrm{~m}^{3}$ was occupied by equipinent. The tank had 39 ports with diameters ranging from 300 to $1220 \mathrm{~mm}$, through which over 1500 instrumentation wires were routed.

The tank vacuum and 84 layers of superinsulation provided the thermal insulation for the LHe-filled coil assemblies and the $\mathrm{LN}$-cooled cold wall that completely lined the inside of the tank. Normally, the turbomolecular pumps were adequate to maintain the vacuum, and the oil diffusion pump was needed only during extensive testing periods when the helium leakage rate was high.

Test stand structure. The test stand structure consisted of a gravity base, the bucking post, and the torque rings, as shown in Fig. 4. The gravity base supported the weight of all the structure plus the six coils and the pulsed coil assembly. It was made up of a six-legged frame supported by rollers on LN-cooled track assemblies. The bucking post, which reacted the centering forces of the energized coils, was a hexagonal column with vertical grooves in each face to align the coils. It was cooled by LHe passages and a reservoir of LHe in its center. Two torque ring subassemblies, top and bottom, supported lateral loads that occurred when the coils were not energized equally.

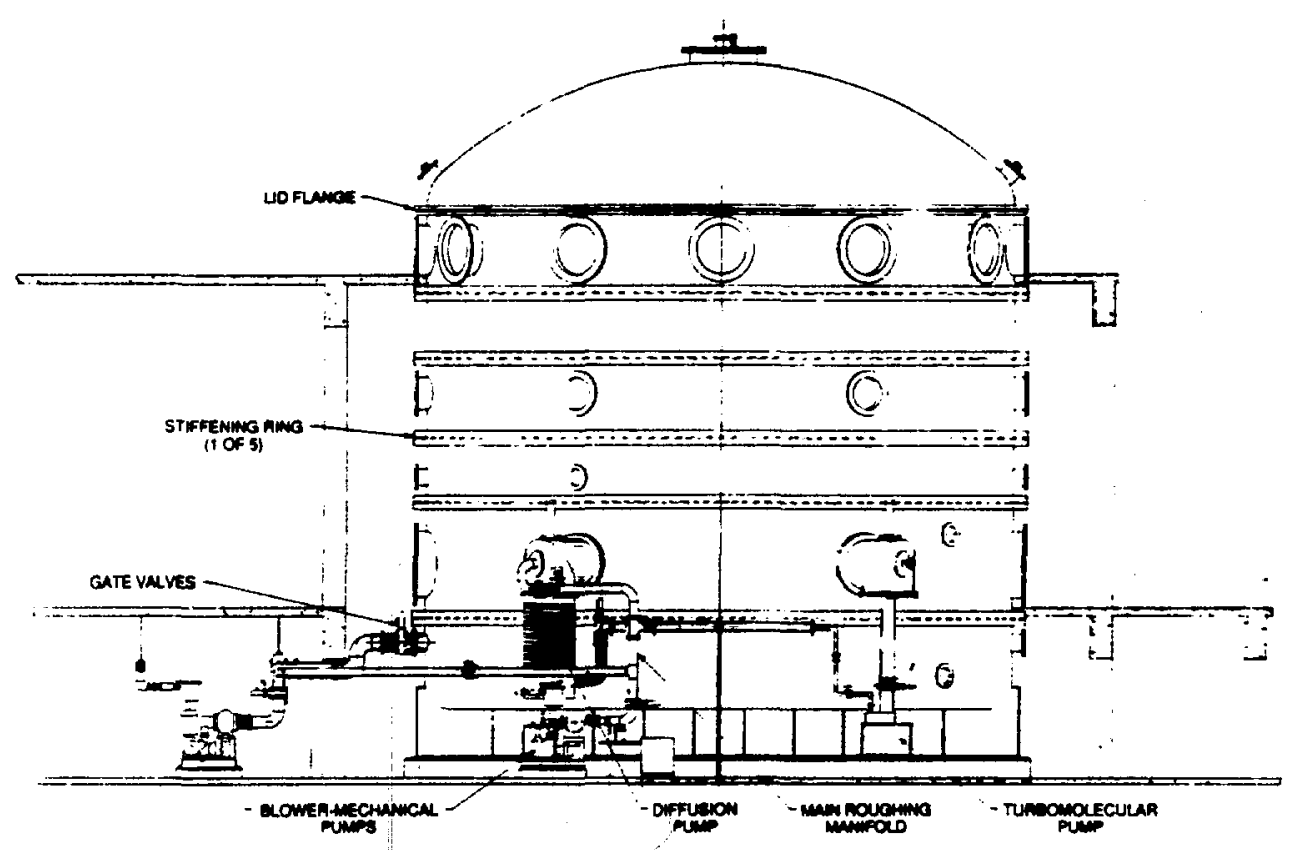

Fig. 3. Vacuum sysiem assembly elevation. 


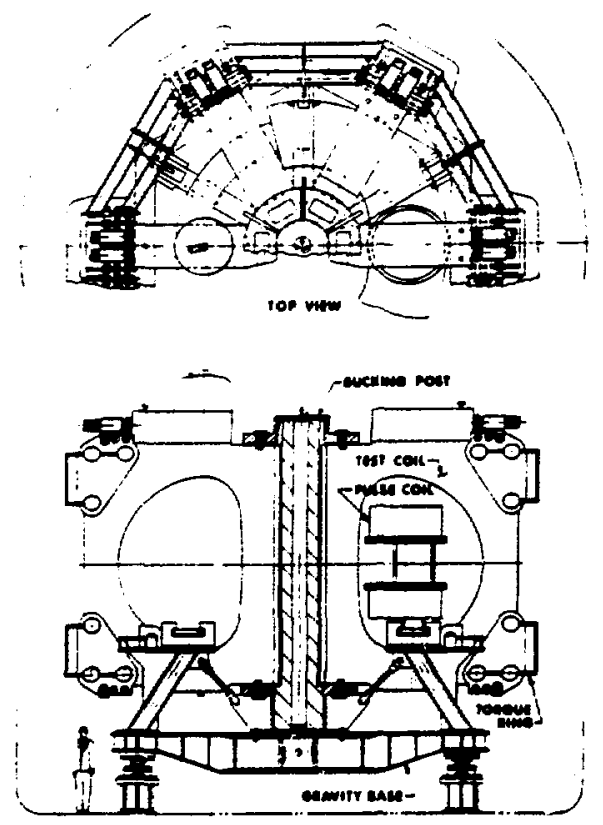

Fig. 4. Elevation and top views of test stand assembly.

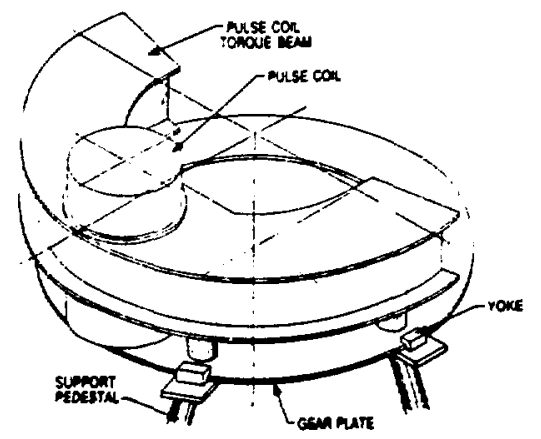

Fig. 5. Pulse coil and torque beam assembly.

Pulsed coil system. To simulate the transient magnetic fields of an operating tokamak reactor, two $\mathrm{LN}$-cooled copper coils were mounted on a rotating torque beam so that they could be moved from coil to coil for individual testing. Figure 5 shows schematically the mounting of the coils. The coils provided a field of $0.15 \mathrm{~T}$ at the test coil winding and could be energized in 1 s to full field, maintained there for 15 s or more, and then ramped down.

The assembly was moved by a system of helium gas pistons operating a pinion and ring gear mechanism. The box beam was supported on rollers during the move, and when it arrived in position for the next test, a set of helium gas-actuated wedges lifted the beam and coils, locking the assembly into position. The beam could rotate almost $360^{\circ}$, so that all six coils could be tested.

Helium system. The helium system cooled the coils and their supporting test stand structure to operating temperature and then supplied helium at the proper pressures and temperatures to the coils, structure, and vapor-cooled current leads. The equipment that performed these functions is shown schematically in Fig. 6.

The refrigerstor system was composed of four major functional parts: gas storage and supply, compression and purification, refrigeration, and utilization. Primary gas storage was in the buffer tanks and storage tanks. The buffer tanks were normally connected to the system and were essential to the smooth operation of the compressors. They accepted excess gas from the high-pressure compressor output and supplied gas as needed to the low- or intermediate-pressure stages. This operation was carried out automatically by the gas management system to maintain the desired operating pressures at all three points. The other storage tanks could also be used for regulation or valved off to preserve an inventory of gas at pressures between about 3 and 15 bar. In addition, a bank of high-pressure storage tanks could store gas up to about 150 bar. Operation of these tanks was controlled manually by the operators as needed. Gas supply was obtained either from the plant or from high-pressure trailers. Maximum gas storage capacity was $1050 \mathrm{~kg}$ at about 17 bar and $450 \mathrm{~kg}$ at about 200 bar.

Compression was accomplished in two stages. The input pressure in the first stage was between 0.4 and 1 bar, with an output of about 3 bar. In the second stage the gas was further compressed to the 15-bar operating pressure. Compressors in the first. 


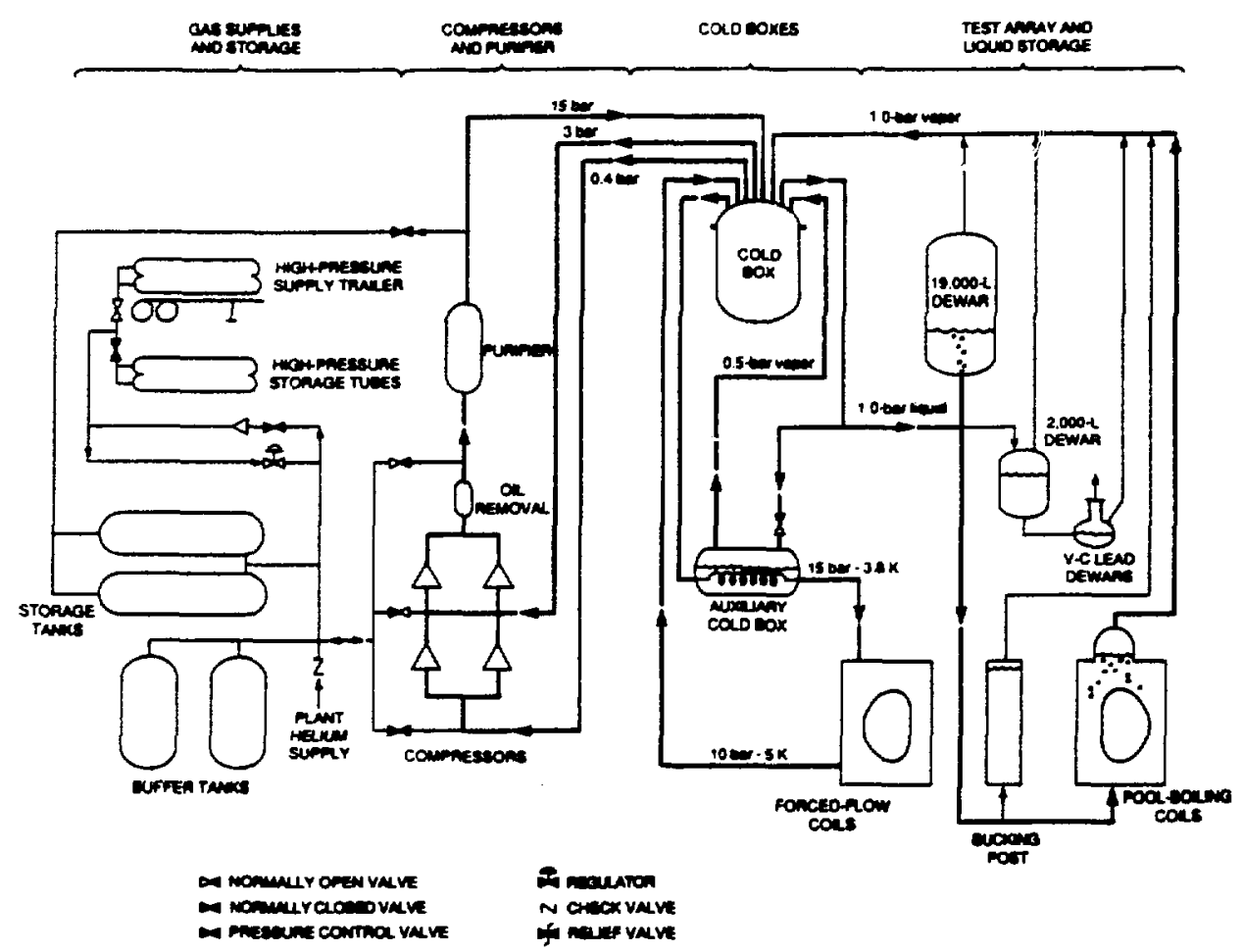

Fig. 6. Overview of helium system.

stage were driven by two 400-hp motors; those in the second stage, by two 1000-hp motors. The oil used for lubricating and cooling the rotary screw compreseors was removed by an elaborate separation system, followed by a purifier containing LNcooled charcoal and molecular sieve adsorbers, which removed $\mathrm{N}_{2}$ and $\mathrm{O}_{2}$ impurities and any remaining oil.

The cold box was made up of heat exchangers, additional purification beds to remove neon and any traces of other gases, and the two gas turbines that extracted heat from the gas, to provide refrigeration. The outputs from the main cold box were cold 15-bar gas, which was further cooled in the auxiliary cold box and supplied to the forced-flow coils, and LHe at 1 bar for the pool-boiling coils, current leads, and storage Dewars. The cold gas from the coils and leads was returned to the cold box.

Delivery of the cold fluids to the coils, leads, and structure completed the operation of the helium system. The multiple paths available were regulated automatically for the most part once a steady-state condition was reached, so that liquid levels and flow rates could be maintained.

Liquid nitrogen system. In addition to providing a cold wall at $99 \mathrm{~K}$ that completely surrounded the coil and structure assembly, the $L N$ system served a number of functions, as shown in Fig. 7. It provided cooling for a shield within the helium transfer lines to intercept heat and prove the efficiency of these vacuum-jacketed lines. It cooled the first heat exchanger in the cold box and in the purifier plus a baffie in the oil-diffusion vacuum pump. Liquid nitrogen was also used to cool the lead Dewnrs and was the coolant for the first part of the cooldown process for the purlsed coils. The liquid was furnished by an outside contractor and stored in two 50,000 -L storage tanks. The flow to the various parts of the system was controlled automatically in steady-state operation and required little operator attention.

Instrumentation and control. Over 2000 sensors of various types provided information on the behavior of the coils and facility and allowed the control of the complex 


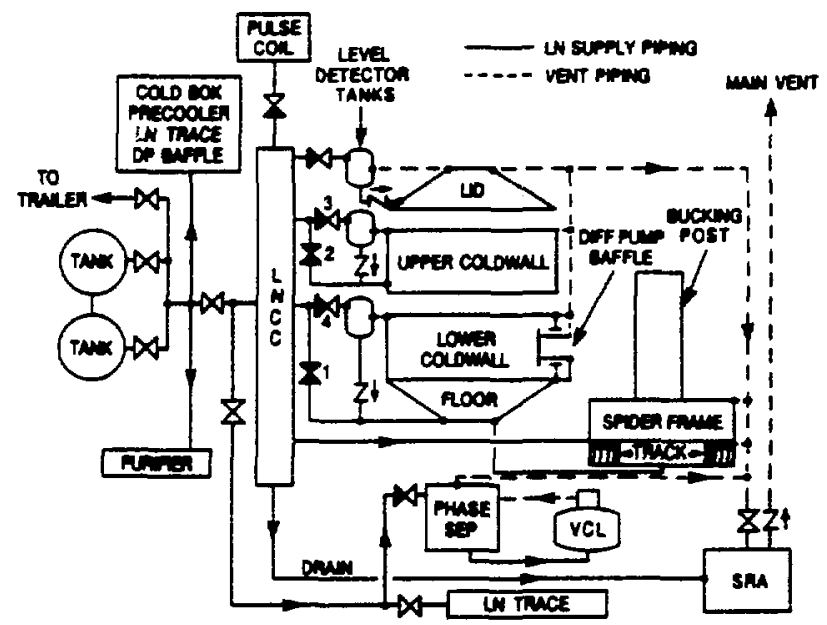

Fig. 7. Schematic of LN system.

system. These sensors included voltage taps, thermometers, strain gages, magnetic field probes, displacement transducers, and helium flow and level sensors. Output from the sensors could be fed directly to the control units to regulate helium levels, for example, and/or into the data acquisition, display, and storage system. Depending on the nature of a signal and its intended use, it could be routed through une or more different front ends. These were called the fast front end, the slow front end, the facility front end, the refrigerator front end, and the transient front end. More detail can be found in Ref. [1].

\section{OPERATION}

Organization. Because of the complexity of the system and the need for precise control of the operations, a formal organizational structure was set up [1]. Basically, operations were performed by teams of trained, certified operators on a $24-h / d a y$ schedule throughout most of the 22 months. A formal operations manual was prepared and updated as procedural revisions occurred. The Head of Operations, who reported directly to the Program Manager, was responsible for safe and effective operations.

Chronology. Table 1 summarizes the operation of the facility from the first evacuation of the tank to the completion of testing nearly five years later.

Table 1. Periods of continuous operation of IFSMTF

\begin{tabular}{clcc}
\hline Run & \multicolumn{1}{c}{ Principal activities } & From & To \\
\hline 1 & Tank evacuation and cold wall operation & $10 / 04 / 82$ & $11 / 06 / 82$ \\
2 & Refrigerator acceptance test, startup & $01 / 17 / 83$ & $05 / 28 / 83$ \\
3 & Refrigerator acceptance test, performarce & $06 / 20 / 83$ & $08 / 30 / 83$ \\
4 & Two-coil cooldown and warmup & $11 / 28 / 83$ & $01 / 29 / 8.4$ \\
5 & Three-coil cooldown, two-coil tests, warmup & $06 / 11 / 84$ & $109 / 28 / 84$ \\
6 & Liquid helium system tests & $04 / 08 / 85$ & $06 / 28 / 85$ \\
7 & Tank evacuation, leak tests, start cooldown & $10 / 21 / 85$ & $12 / 23 / 85$ \\
8 & Six-coil cooldown, coil tests & $01 / 16 / 86$ & $12 / 23 / 86$ \\
9 & Continued six-coil tests & $01 / 05 / 87$ & $09 / 01 / 87$ \\
\hline
\end{tabular}


Cooldown. The six-coil array was cooled to operating temperature in less than 30 days. The first stage used the heat exchanger built into the cold box to allow the helium gas flow to be cooled with LN. By mixing the cold gas with room-temperature gas, the prescribed maximum temperature difference of $50 \mathrm{~K}$ between the coils and the facility structure could be maintained. When the array reached $100 \mathrm{~K}$, cooling was interrupted for a few days while an inventory of LHe was built up in the large storage Dewar. Cooling in the range between $100 \mathrm{~K}$ and about $14 \mathrm{~K}$ used the first-stage turboexpander and was limited by its power capability of about $11 \mathrm{~kW}$ initially, decreasing to $6 \mathrm{~kW}$ at the lower temperature. The final cooling was accomplished using the LHe accumulated for this purpose. Figure 8 shows how the cooling progresserl with time. This was the only complete cooldown of the entire facility during the 22 -month period.

Operation. Since the primary purpose of the facility was the testing of the coils, the most significant part of the operation was the performance of the system during periods of testing. Operating time was limited by the fact that refrigeration was not adequate to maintain full-scale testing on a continuous basis. This was not inconsistent with the testing program, however, because testing had to be stopped periodically for a number of reasons. These included the need to change the configuration (e.g., moving the pulse coil or changing the instrumentation leads) or even to provide a rest period for the experimenters. During such less-active periods, the facility was operated in a stand-by mode that allowed the LHe inventory to be replenished. Figure 9 shows the helium inventory over about a three-week period of particularly active testing.

The most dramatic occurrence for the helium inventory is a six-coil dump. During routine testing without dumps, the overall tendency was to gain in inventory. This trend was evident whenever the system was operating at its best. At times, however, problems created delays in the testing program, as might be expected in such a complex experimental system.

Availability. To evaluate the performance of the system, a special definition of availability was used. Simply stated, the system is "available" when the condition of the facility permits "coil testing activities" to proceed. "Coil testing activities"

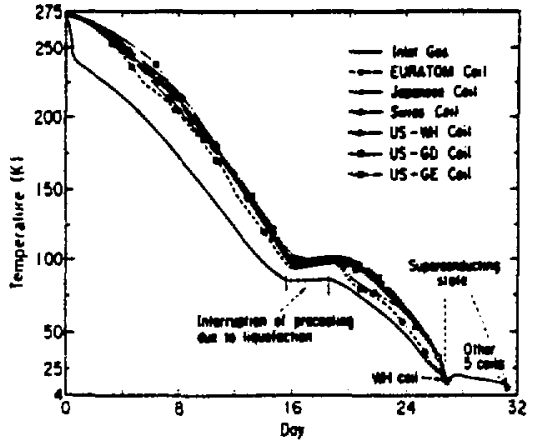

Fig. 8. Temperatures of helium inlet gas and coils during cooldown (day 0 was January 18,1986$)$.

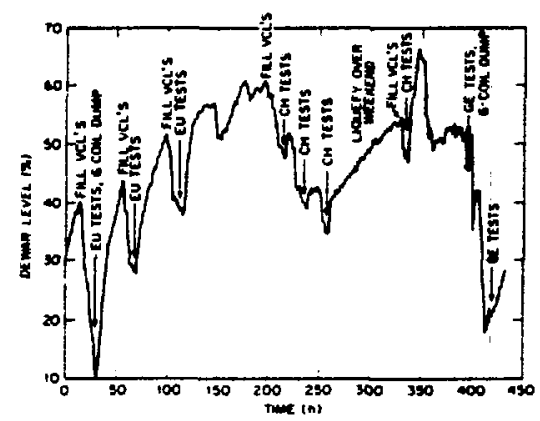

Fig. 9. Level in the 19,000-L Dewar during a particularly active period of coil testing.

\section{REPRODUCED FROM BEST AVAlLABLE COPY}


include the normal tasks required either before or after energizing the cuils and procuring data, such as preparing the instrumentation configuration, reliquefying the helium boiled off in the test, and night and weekend rest for the experimenters. From this definition an availability factor, the fraction of time that the facility was available, could be obtained. This factor is displayed in Figs. 10-13, covering both the perion of two-coil operation in 1983-1984 and the six-coil array tests in 1985-1987. These figures show the major activities and factors affecting the availability of the facility. Reasons for major periods of unavailability are listed in Table 2.

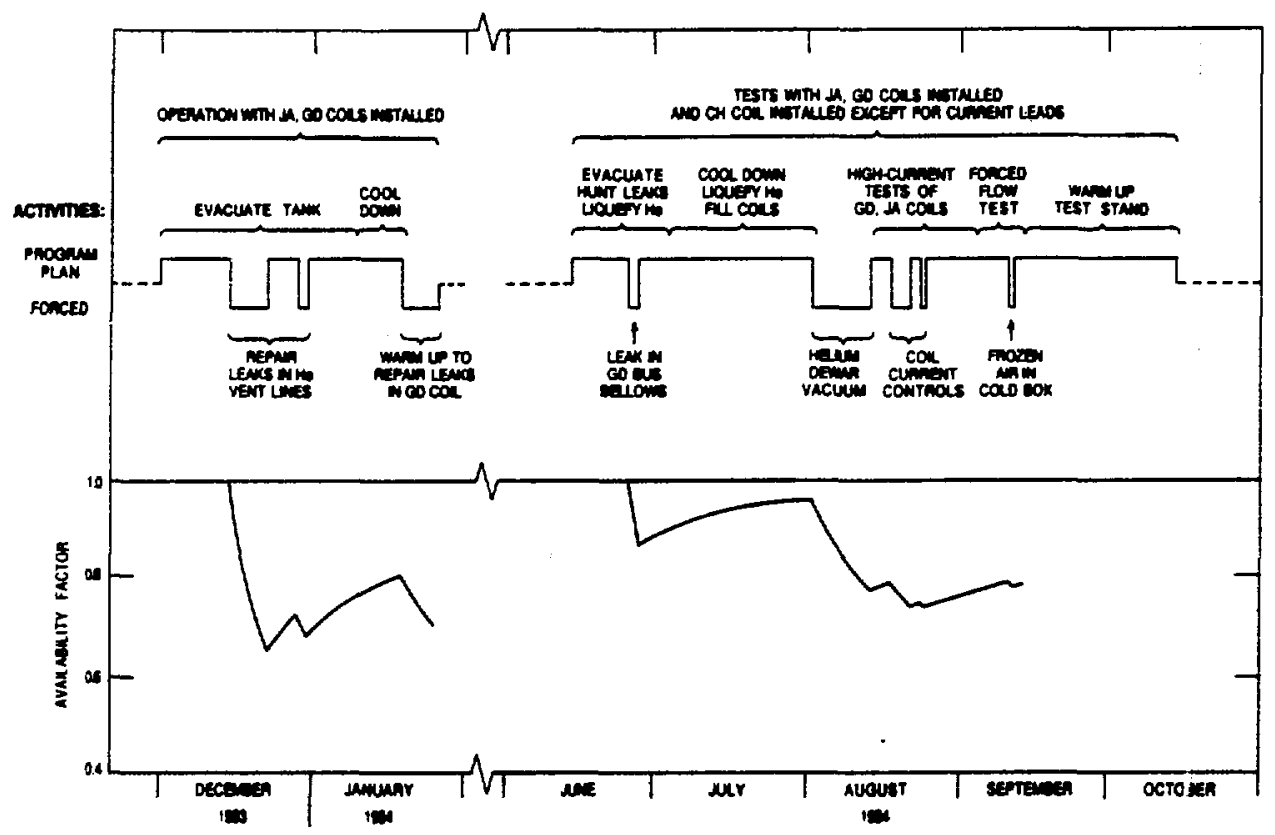

Fig. 10. Principal activities and availability factor for December 1983-October 1984.

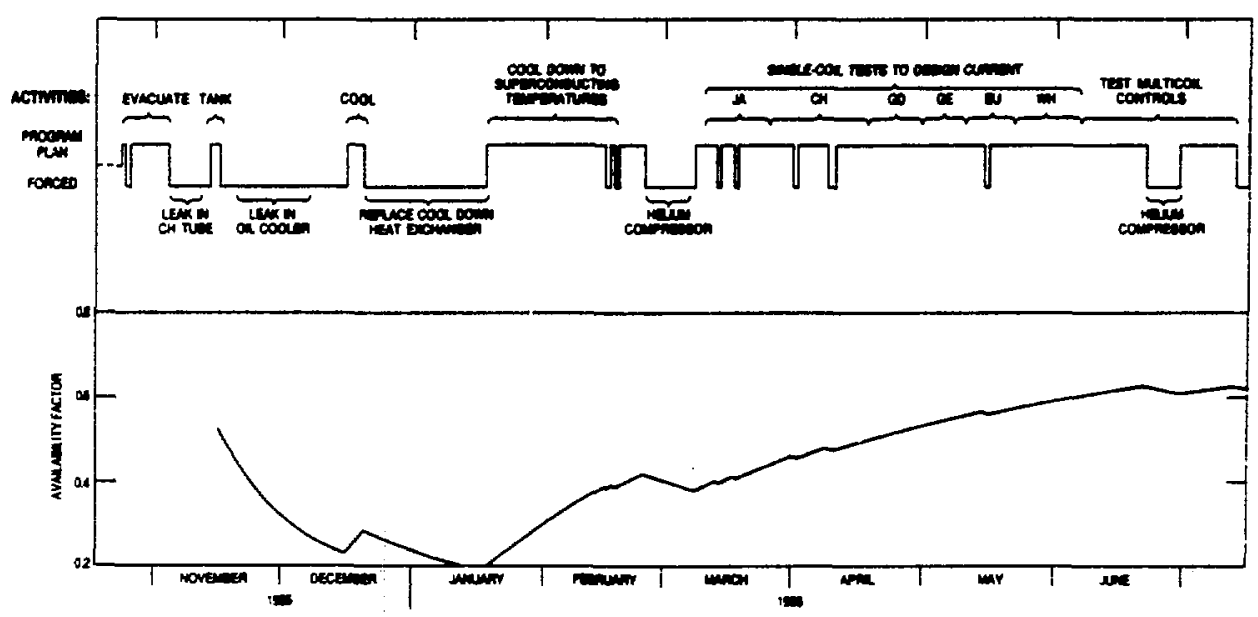

Fig. 11. Principal activities and availability factor for November 1985-June 1986. 


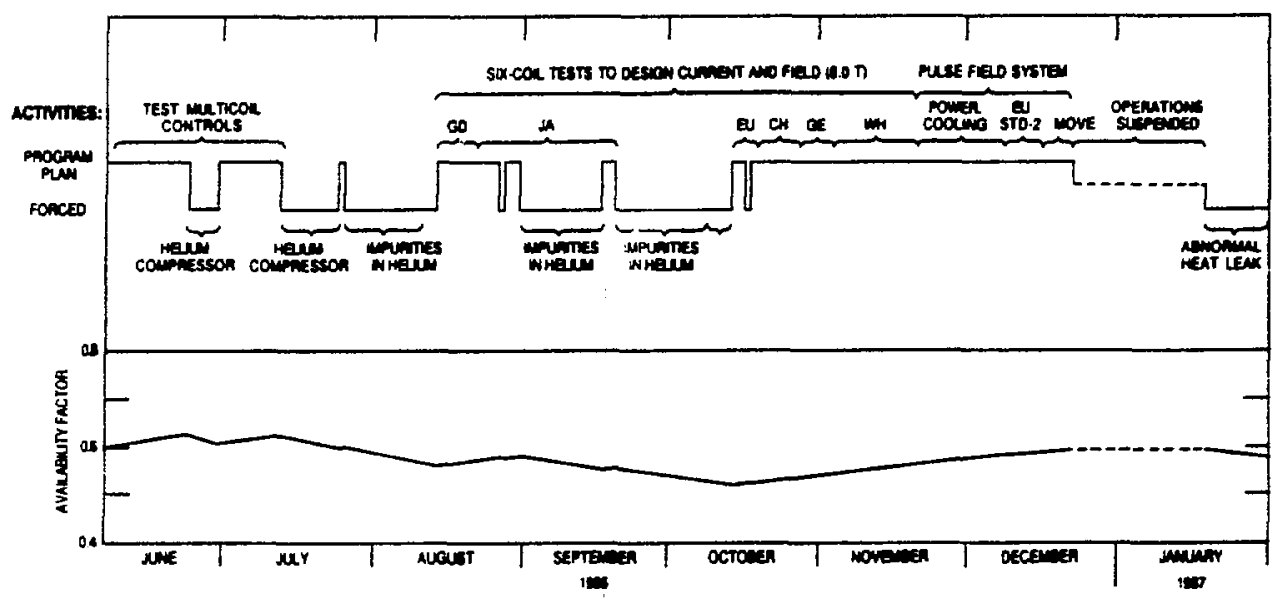

Fig. 12. Principal activities and availability factor for June 1986-January 1987.

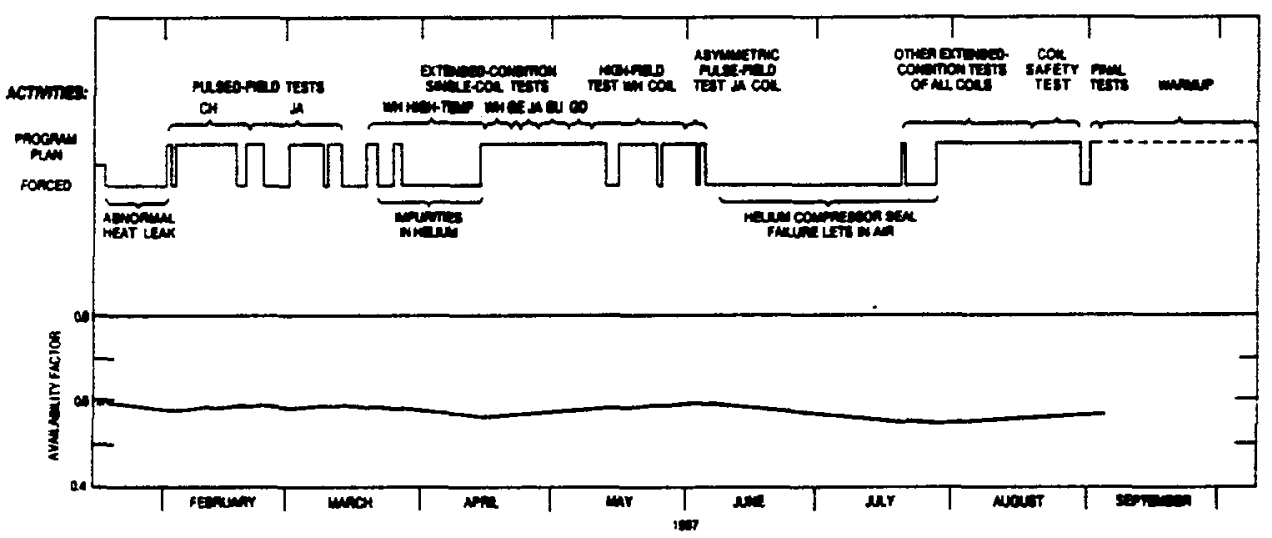

Fig. 13. Principal activities and availability factor for February-September 1987.

\section{CONCLUSIONS}

The overall availability of the system, almost $60 \%$, was considered a qualified success. In fact, only one element of the entire facility-the pulsed coil system-was unable to complete its planned program. After the assembly had been successfully moved twice to new locations and used to test three of the coils, excessive leakage in the gas-actuated pistons led to the abandonment of further tests.

The word "leak" is prominent in Table 2. Many other items, such as impurity problems, are directly attributable to leaks into the system. So, one lesson to be learned from the operation of this system is the importance of preventing all types of leakage, into and out of the system. Another common problem, the occasional loss of utilities, had been anticipated and occurred about as frequently as expected. Although providing backup for all utilities would have been impractical, a secondary instrument air source was added during the operating period, and an alternate conling water source was available from the beginning. 
Table 2. Intervals of unavailability and controlling reasons

\begin{tabular}{|c|c|c|c|c|c|}
\hline $\begin{array}{l}\text { Month/ } \\
\text { year }\end{array}$ & $\begin{array}{l}\text { Daye } \\
\text { low }\end{array}$ & Controllies renow & $\begin{array}{l}\text { Month/ } \\
\text { year }\end{array}$ & $\begin{array}{l}\text { Deye } \\
\text { lout }\end{array}$ & Controlling reseon \\
\hline $10 / 05$ & $\mathbf{I}$ & 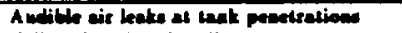 & $10 / 8$ & I & 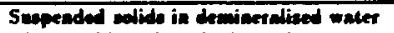 \\
\hline $11 / 95$ & 7 & Heliun bak in $\mathrm{CH}$ coil & $1 / 67$ & 14 & A beorian beat bak (polec coil \\
\hline $11 / 85$ & $\mathbf{3}$ & 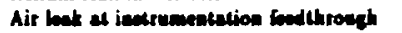 & & & powr leadel \\
\hline $11 / 85$ & 1 & Heliug oil rewoval gyetem (inctallation) & $2 / 87$ & $\mathbf{t}$ & Pule coil powee controlo \\
\hline $12 / 03$ & 17 & Wale leat in belien conpriener & $2 / 87$ & 1 & FF coil tow control \\
\hline & & oil coober & $2 / 87$ & 2 & Low of plant electriced pomet \\
\hline $\begin{array}{l}12 / 83 \\
1 / 86\end{array}$ & 20 & 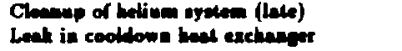 & $2 / 07$ & 6 & $\begin{array}{l}\text { Helium lowh from pulate coil movement } \\
\text { actureor }\end{array}$ \\
\hline & & (neplecenems) & $3 / 87$ & 1 & Swepended solides in deminerelied water \\
\hline 2/86 & 1 & Waler lowk is tueboerpeceder coolet & $3 / 107$ & 3 & Inevlation on VCL tange bolls \\
\hline $2 / 86$ & 1 & Low of plant inatronest air enpely & $3 / 07$ & 3 & Helium compremor electrical pomer \\
\hline $2 / 80$ & 10 & $\begin{array}{l}\text { Despers in belium comprenor No. } 4 \\
\text { (replecenene) }\end{array}$ & $3 / 07$ & 4 & $\begin{array}{l}\text { brester } \\
\text { Frosew ivpmrition in cold box }\end{array}$ \\
\hline $3 / 80$ & 2 & 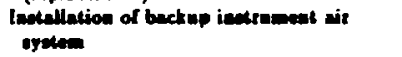 & $\begin{array}{l}1 / 07 \\
5 / 07\end{array}$ & 18 & $\begin{array}{l}\text { Frowem impuritien in cold bor and purifer } \\
\text { Low of plant electrienl power }\end{array}$ \\
\hline $3 / \mathbf{n}$ & I & Low of plamb doetried power & 3/et & 1 & Coil power muply switch actnasor \\
\hline $3 / 80$ & 1 & Dete sequimition syetem freet end & $3 / 07$ & 1 & 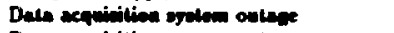 \\
\hline $3 / 100$ & $\mathbf{I}$ & Frowe aic in beline be from JA coil & 6/07 & 1 & 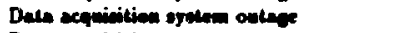 \\
\hline$+/ 100$ & 2 & Low of plask electrical pour & 4/87 & 5 & 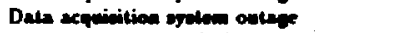 \\
\hline $\begin{array}{l}5 / 86 \\
6 / 86\end{array}$ & 1 & 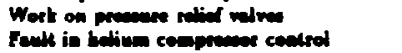 & $7 / 07$ & 40 & 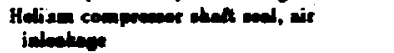 \\
\hline $7 / 86$ & 12 & Les of pland dectricil powr and: & T/107 & 2 & Treen of eir in belian \\
\hline & & & $7 / 117$ & 5 & Helim cenpreser ail leat \\
\hline $8 / 84$ & 10 & Presen inperition in celd bex and parifer & $\boldsymbol{\theta} / \mathbf{0 7}$ & 2 & Low of plast dectrical powet \\
\hline $\begin{array}{l}8 / 86 \\
8 / 86\end{array}$ & $\begin{array}{l}3 \\
1\end{array}$ & 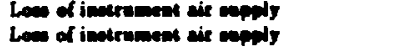 & $\overline{10 / 106-}$ & $\overline{214}$ & All canen (2044 ont of ast daye) \\
\hline $9 / 26$ & 17 & Fresen inperition in celd bee & $9 / 17$ & & \\
\hline $9 / 86$ & 19 & 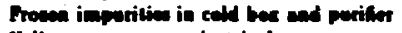 & & & \\
\hline $10 / 88$ & $\mathbf{s}$ & 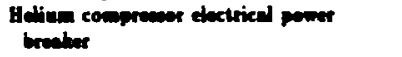 & & & \\
\hline
\end{tabular}

\section{ACKNOWLEDGMENTS}

The author would like to give credit to the many individuals involved in these tests who contributed greatly to the successful operation of the facility. Eapecially crucial to this echievement were the operators/technicians and the three operation supervisors who kept the system going when problems arose. Also, the help of our secretaries, Lois Scrugga, Kathie Zell, and Sandra Vaughan, was indispensable in the uperations phase and in the preparation of this and other reports on the program. Finally, the encouragement and support of the program manager, Paul Haubenreich, are greatly appreciated.

\section{REFERENCES}

(1) A thorough account of the entire program, with references too numerous to cite here, is contained in "The IEA Large Coil Task: Development of Superconducting Toroidal Field Magnets for Fusion Power," (D S. Beard et al., eds.), Fusion Eng. Des., 7, 1-232 (1988).

\section{REPRODUCED FROM BEST AVAILABLE COPY}

